\title{
On the Penetration of Light into Sea Water.
}

\author{
By
}

H. H. Poole, Sc.D.,

Chref Scientific Officer of the Royal Dublin Society

AND

W. R. G. Atkins, Sc.D., F.R.S.,

Head of the Department of General Physiology at the Plymouth Laboratory.

With 3 Figures in the Text.

An account has recently been given by one of us (1) of a telephone method of measuring photo-electric currents, which enables measurements of submarine illumination to be made in a small vessel by means of photoelectric cells; also of some preliminary measurements made by its aid near Plymouth, in the autumn of 1924. The present paper contains a brief description of the apparatus employed, and a record of the results of further observations made on board the steam trawler Salpa, belonging to the Marine Biological Association, near Plymouth in the autumn of 1925. For details as to the construction of the apparatus reference must be made to the previous paper.

\section{Method of Measuring the Photo-Electric Current.}

Fig. 1, which is reproduced from the previous paper, shows the general scheme of the electrical connections. All subsidiary circuits, such as the potentiometer standard cell, the amplifier circuits, etc., have been omitted from the diagram for the sake of simplicity. B is the high tension battery, of the usual wireless receiver type, which provides the anode potential for whichever of the photo-electric cells, D or E, is plugged into it. The current, which passes through the cell when exposed to light, also passes through a "Zenite" wire resistance, R, of 51,300 ohms, and a similar safety resistance, $\mathrm{S}$, of about $19,000 \mathrm{ohms}$. The potential difference between the ends of $\mathrm{R}$ is measured by means of a potentiometer, P. Telephones, T, are used to detect any current due to lack of balance, this current being rendered intermittent by means of a special form of interrupter, I. The sensitivity is increased to a suitable extent by means of a two-stage Marconi note magnifier, A, the amplification being controlled by varying the filament currents of the valves. The condenser, C, also increases the sensitivity. Guard ring wires, to prevent errors due to surface leakage, are connected to the negative terminal N. 
The interrupter, which is worked by an electric buzzer, forms an independent unit, which must be kept 5 or 6 feet away from the other circuits to prevent induction effects. The rest of the apparatus, with the exception of the photometers and their leads, and, of course, the head telephones, is rigidly mounted in a strong wooden box, which can be firmly lashed to the bench in the deck cabin in which the apparatus is set up. Thus even violent motion of the ship does not interfere with the taking of readings.

As this cabin is generally warm and dry very little trouble has been experienced afloat from "dark currents," i.e. leakage currents which prevent the potentiometer from reading zero when the photometer is screened from light. This effect, as mentioned in the previous paper, was sometimes troublesome when the apparatus was exposed on an open pier, so that dew was liable to deposit on the insulating surfaces.

\section{Photometers and Photo-Electric Cells.}

Two photometers are employed. One, which we will call the air photometer, consists of a light-tight wooden box with a sheet metal cover, in the centre of which is a circular aperture $5 \mathrm{~cm}$. in diameter closed by a thin glass window, which is fixed to the under side of the cover with waterproof cement. The under side of this window is coated with the special matt varnish used for obscuring electric lamps. In contact with this surface is an opaque screen of black card with a central aperture $2.4 \mathrm{~cm}$. in diameter, forming the pupil of the photometer. This method of mounting ensures that the pupil receives light from almost a complete hemisphere, the screening due to the thin sheet metal surrounding the window being negligible.

A vacuum photo-electric cell made by the General Electric Company is mounted inside the box so that its pupil is almost in contact with the diffusing surface at the centre of the window.

The photometer is mounted on gimbals, so that its diffusing surface remains very nearly horizontal, independent of the motion of the ship. It is carried on the roof of the deck house in a position as free as possible from all shading by spars and rigging, and is connected to the measuring apparatus by rubber insulated flexible leads.

The water photometer is shown in part section in Fig. 2. The case is a massive one of gun-metal, and the window is of plate glass $1 \mathrm{~cm}$. thick, the joints being made with sheet rubber gaskets. The under side of this window is also coated with matt varnish, and the effective diameter of the pupil is limited to $2 \cdot 4 \mathrm{~cm}$. by an annulus of black card. The general construction is fairly evident from the figure, which shows the leads, 
PENETRATION OF LIGHT INTO SEA-WATER.

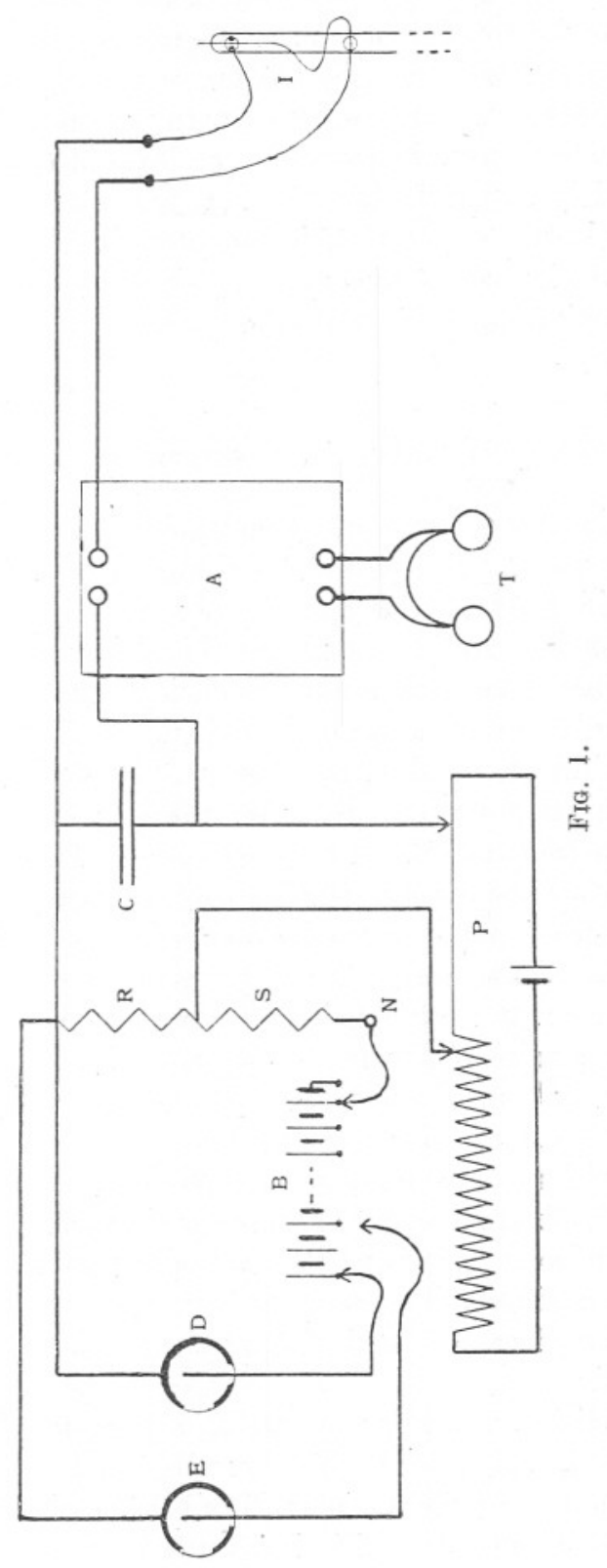


of high tension ignition cable, $11 \mathrm{~mm}$. outside diameter, and one of the four supporting wire ropes, which form a bridle suspending the photometer with the window horizontal. An external metal shutter enables all light to be cut off from the photometer, and can be worked by strings, so that " dark currents" can be tested with the photometer submerged. This shutter, when open, drops below the level of the window, so that it cannot possibly cast a shadow on it.

The photo-electric cell, which is mounted just below the diffusing surface, is of the Kunz gas-filled type, in which the sensitivity is greatly increased by ionisation due to collision.

\section{Optical Considerations.}

We must evidently define what we mean by the illumination at a given point in air or water. The problem is complicated by the fact that we have to deal with light travelling in many different directions, the angular distribution varying greatly at different times, and being quite different in the two media. Thus with a uniform cloudy sky the angular distribution of the light in air may be approximately uniform over one hemisphere. In addition to this direct sky light there will be some light reflected off the water. This does not directly affect the air photometer or the submarine illumination, and is disregarded here. The illumination just below a smooth water surface will be confined within a cone of semivertical angle $48.5^{\circ}$, and will not be uniformly distributed throughout this solid angle. On the other hand, if the sun is shining perhaps $75 \%$ of the light in air may be direct sunlight, and may be treated as parallel rays making a definite angle with the horizon. Below the water surface these rays will, of course, still form a parallel beam, but inclined more steeply to the horizon, owing to refraction.

Several definitions of illumination are possible. Thus we may define the Vertical Illumination as the illumination in metre candles falling on a horizontal surface. This is what is actually measured by the photometers when certain small corrections have been applied for reflection losses at the front faces of the glass windows, and is denoted throughout by the letter $\mathrm{V}$.

Another definition, which is very useful in photometric measurements on shore, is the illumination in metre candles on a surface set to catch the maximum amount of light. We will call this the Maximum Illumination, and denote it by the letter M. Evidently in the case of pure sunlight the photometer must be set perpendicular to the sun's rays. For actual sunlight, which contains some diffuse sky light, a setting rather nearer the horizontal would receive more light. This setting of the photometer 


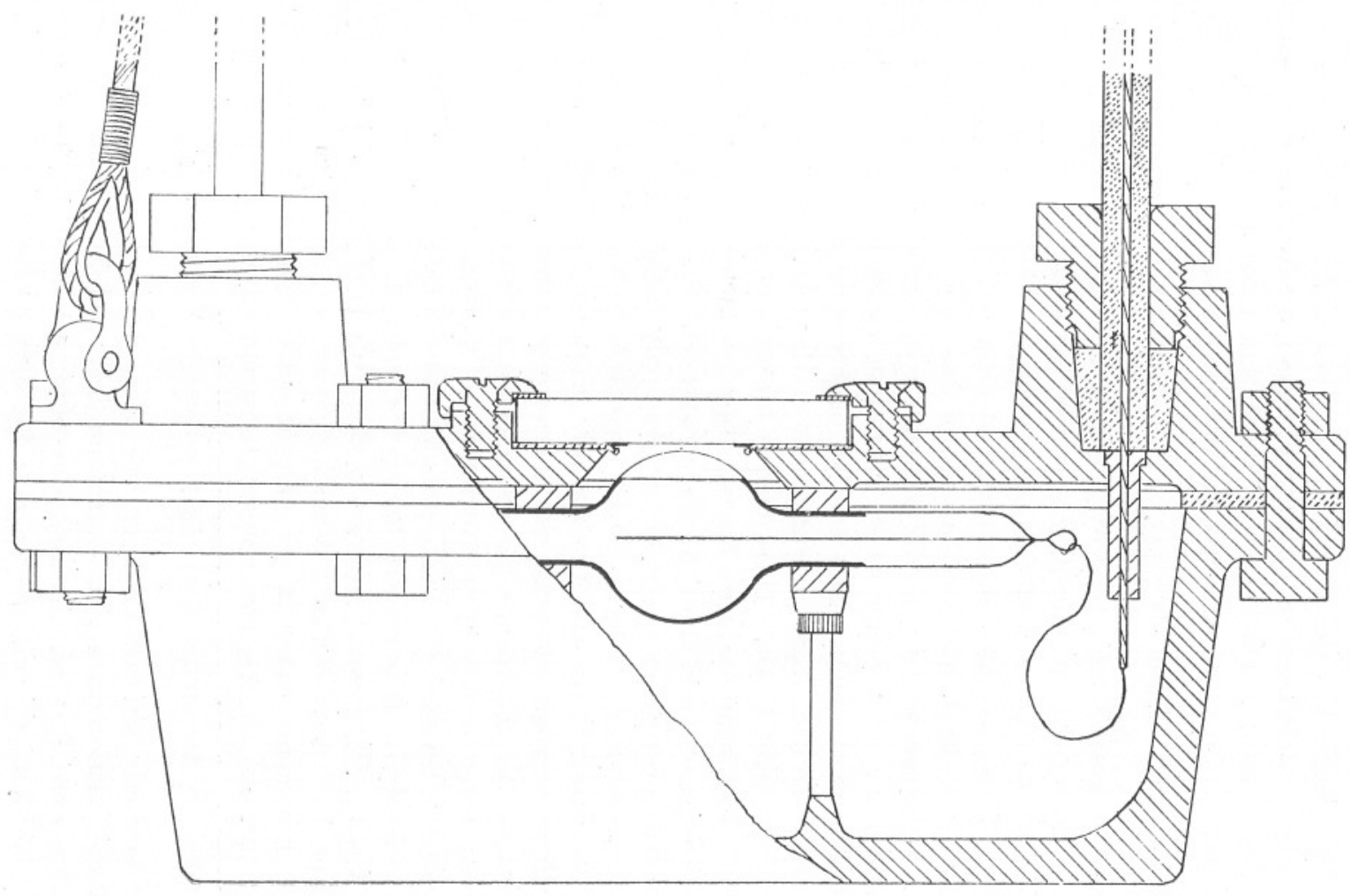


with its surface in a definite plane other than the horizontal is easy on shore, but would be most inconvenient afloat.

A third definition is the one which was adopted in the previous paper, being there denoted by the letter I. It may be called the Total Illumination, and measures the total quantity of light regardless of angle, being defined as follows: Let $i d \Omega$ be the illumination in metre candles due to a small pencil of rays of solid angle $d \Omega$ on a small area placed perpendicular to the pencil. Then $I=\int_{0}^{2 \pi} i d \Omega$. This measures the total illumination that is available for photosynthesis at a given point (neglecting, however, reflected light travelling upwards), although no single surface could be set to receive it all at once, except in the ideal case of pure sunlight. It is probably the best way of recording the photosynthetic activity of the light, and for that reason was adopted in the previous paper. Unfortunately it can only be found from the photometer reading by multiplying by a factor whose magnitude depends on the angular distribution of the light. This can be roughly estimated, knowing the altitude of the sun, from measurements of the relative proportions of sun and sky light in air. These factors for air and water were, in the previous paper, combined with the reflection loss factors, and in this way I was directly obtained from the photometer reading. As, however, the reflection loss correction is a small one, and only slightly affected by the angular distribution, it seems to be preferable to apply it separately, and thus obtain $\mathrm{V}$, the quantity actually measured by the photometer. Accordingly in what follows all results are stated in terms of the Vertical Illumination V. The factor for deducing the corresponding value of I for air or water for any given distribution of light may be obtained by interpolation between the pure sunlight and diffused sky light values given in Table 1. It is evident that, for a point in air lit by pure sunlight, $\mathrm{I}_{\mathrm{a}}=\mathrm{M}_{\mathrm{a}}=\mathrm{V}_{\mathrm{a}} \operatorname{cosec} \alpha$, where $\alpha$ is the altitude of the sun, and the subscript "a" denotes that the medium is air, for, in this case, to find M the photometer should be set perpendicular to the sun's rays, and, since $i$ vanishes all over the hemisphere except in the small solid angle subtended by the sun's disc, $\int_{0}^{2 \pi} i d \Omega$ reduces to M simply.

For perfectly diffused light, on the other hand, $M_{a}=V_{a}$, since the horizontal position catches the maximum light, and, as $i$ is uniform over the hemisphere, $\mathrm{I}_{\mathrm{a}}=2 \pi i$. An easy piece of integration shows that, under these conditions, $\mathrm{V}_{\mathrm{a}}=\pi i$. So we have for diffused light $\mathrm{I}_{\mathrm{a}}=2 \mathrm{M}_{\mathrm{a}}=2 \mathrm{~V}_{\mathrm{a}}$.

For a point just below a smooth water surface we have, for pure sunlight, $\mathrm{I}_{\mathrm{w}}=\mathrm{M}_{\mathrm{w}}=\mathrm{V}_{\mathrm{w}} \operatorname{cosec} \theta$, where $\theta$, the angle between the refracted ray and the horizon, is connected with $\alpha$ by the relation $\cos \alpha=1 \cdot 333$ $\cos \theta$. It is evident that $\mathrm{V}_{\mathrm{w}}$ must be somewhat less than $\mathrm{V}_{\mathrm{a}}$, since a beam 
of such a width as just to cover a given horizontal area in air would still cover the same horizontal area in water, and some of the light would be reflected from the surface. Hence, since $\operatorname{cosec} \theta$ is always less than $\operatorname{cosec} a$, there must be a still greater reduction in I in passing through the surface. By making use of Fresnel's formulæ for the reflection losses we can calculate the ratios $\frac{V_{w}}{V_{a}}$ and $\frac{I_{w}}{I_{a}}$. These are shown in the table. It will be noticed that for low altitude sunlight the reduction in total illumination caused by the surface is much greater than the reduction in vertical illumination.

For diffused light it is evident that, as before, $\mathrm{M}_{\mathrm{w}}=\mathrm{V}_{\mathrm{w}}$. To find the relations between $V_{w}$ and $I_{w}$ and the corresponding air values $V_{a}$ and $I_{a}$ we proceed as follows. The sky is divided into nine zones, the extension of each in altitude being $10^{\circ}$. Then, assuming the sky to be uniformly bright, each zone will contribute a total illumination proportional to its area, and at a mean altitude equal to the mean altitude of the zone. Since in finding either $V_{w}$ or $I_{w}$ we are not concerned with the azimuth of the rays, we may represent the effect of each zone as that of a beam of the corresponding intensity and altitude. We thus have to find the effect in water produced by nine beams of known relative intensities, and of altitudes (in air) $5^{\circ}, 15^{\circ}, \ldots 85^{\circ}$. Using the factors already found for the different altitudes, we find the corresponding values of $\mathrm{M}_{\mathrm{w}}$ for the nine beams. Then evidently $\mathrm{I}_{\mathrm{w}}=\Sigma \mathrm{M}_{\mathrm{w}}$ and $\mathrm{V}_{\mathrm{w}}=\Sigma \mathrm{M}_{\mathrm{w}} \sin \theta$, the summation in each case consisting of nine terms. Hence we find the values of $\frac{I_{w}}{V_{w}}, \frac{V_{w}}{V_{a}}$, and $\frac{I_{w}}{I_{a}}$ for diffused light, as given in the last line of the table, the value of $\frac{I_{a}}{V_{a}}$ being 2 , as already pointed out. The corresponding mean values of $\alpha$ and $\theta$ are obtained from those of $\frac{I_{a}}{V_{a}}$ and $\frac{I_{w}}{V_{w}}$ respectively.

Actual daylight may be represented as a mixture of pure sunlight and perfectly diffused sky light. This is obviously only a rough approximation as the sky is seldom uniformly bright all over, but it is the best that is practicable. An estimate of the relative proportions of sunlight and sky light can be made by taking readings of the air photometer when freely exposed, and when shaded from direct sunlight by the interposition of a small object at a distance of several feet. If $\beta$ is the ratio of the unshaded to the shaded reading it can be shown that $x=x_{1}+$ $\frac{x_{2}-x_{1}}{\beta}$ approximately, where $x$ is the required value of any factor, and $x_{1}$ and $x_{2}$ are the values for pure sunlight (of the correct altitude) and diffused light, respectively. Under $f$ in Table 1 are shown 
values for the reflection loss factor as explained in the following section :-

\section{TABLE 1.}

\begin{tabular}{|c|c|c|c|c|c|c|c|c|}
\hline \multirow{2}{*}{\multicolumn{2}{|c|}{ Pure Sunlight }} & \multirow{3}{*}{$\begin{array}{c}a \\
5^{\circ} \\
10\end{array}$} & \multicolumn{2}{|c|}{$\theta \quad \operatorname{cosec} a=\frac{\mathrm{I}_{\mathrm{a}}}{\mathrm{V}_{\mathrm{a}}}$} & $\mathrm{a}$ & \multirow{2}{*}{$\begin{array}{l}\frac{V_{\mathrm{w}}}{\mathrm{V}_{\mathrm{a}}} \\
0 \cdot 42\end{array}$} & \multirow{2}{*}{$\begin{array}{c}\frac{I_{w}}{I_{a}} \\
0 \cdot 055\end{array}$} & \multirow{2}{*}{$\begin{array}{c}f \\
2 \cdot 50\end{array}$} \\
\hline & & & $41 \cdot 7^{\circ}$ & $11 \cdot 47$ & $1 \cdot 505$ & & & \\
\hline & , & & $.42 \cdot 4$ & $5 \cdot 76$ & $1 \cdot 485$ & $0 \cdot 65$ & $0 \cdot 17$ & $1 \cdot 56$ \\
\hline , & , & 15 & $43 \cdot 6$ & $3 \cdot 86$ & $1 \cdot 45$ & $0 \cdot 79$ & $0 \cdot 295$ & $1 \cdot 295$ \\
\hline , & , & 20 & $45 \cdot 2$ & $2 \cdot 92$ & $1 \cdot 41$ & $0 \cdot 87$ & $0 \cdot 42$ & $1 \cdot 16$ \\
\hline , & , & 25 & $47 \cdot 2$ & $2 \cdot 37$ & $1 \cdot 365$ & $0 \cdot 915$ & 0.525 & $1 \cdot 095$ \\
\hline , & , & 30 & $49 \cdot 5$ & $2 \cdot 00$ & $1 \cdot 315$ & $0 \cdot 94$ & $0 \cdot 62$ & $1 \cdot 06$ \\
\hline , & , & 35 & $52 \cdot 1$ & $1 \cdot 745$ & $1 \cdot 265$ & 0.955 & $0 \cdot 695$ & $1 \cdot 93$ \\
\hline, & , & 40 & $54 \cdot 9$ & $1 \cdot 555$ & $1 \cdot 22$ & 0.965 & $0 \cdot 76$ & $1 \cdot 02$ \\
\hline " & , & 45 & $58 \cdot 0$ & $1 \cdot 415$ & $1 \cdot 18$ & 0.975 & $0 \cdot 815$ & $1 \cdot 015$ \\
\hline , & , & 50 & $61 \cdot 2$ & $1 \cdot 305$ & $1 \cdot 14$ & 0.975 & 0.855 & $1 \cdot 01$ \\
\hline ", & , & 55 & $64 \cdot 5$ & $1 \cdot 22$ & $1 \cdot 11$ & $0 \cdot 98$ & $0 \cdot 89$ & 1.005 \\
\hline, & , & 60 & $68 \cdot 0$ & $1 \cdot 155$ & $1 \cdot 08$ & 0.98 & 0.915 & $1 \cdot 005$ \\
\hline ", & , & 65 & $71 \cdot 5$ & $1 \cdot 105$ & 1.055 & $0 \cdot 98$ & $0 \cdot 94$ & $1 \cdot 00$ \\
\hline , & , & 70 & $75 \cdot 1$ & $1 \cdot 065$ & $1 \cdot 035$ & 0.98 & 0.955 & $1 \cdot 00$ \\
\hline, & , & 75 & $78 \cdot 8$ & $1 \cdot 035$ & $1 \cdot 02$ & 0.98 & 0.965 & $1 \cdot 00$ \\
\hline , & , & 80 & $82 \cdot 5$ & $1 \cdot 015$ & $1 \cdot 01$ & 0.98 & $0 \cdot 97$ & $1 \cdot 00$ \\
\hline ," & , & 85 & $86 \cdot 3$ & $1 \cdot 005$ & $1 \cdot 00$ & 0.98 & 0.975 & $1 \cdot 00$ \\
\hline , & & 90 & $90 \cdot 0$ & $1 \cdot 00$ & $1 \cdot 00$ & $0 \cdot 98$ & 0.98 & $1 \cdot 00$ \\
\hline Diffu & Light & $30 \cdot 0$ & $57 \cdot 0$ & $2 \cdot 00$ & $1 \cdot 19$ & 0.935 & 0.56 & 1.06 \\
\hline
\end{tabular}

\section{Reflection Losses at Photometer Windows.}

Since it is obviously necessary to protect the diffusing surfaces, these form the inner faces of the glass windows. We must, accordingly, correct for the variation with obliquity of the reflection loss at the front surface of the window, and for the effect of the external medium. We can, as before, calculate the loss for any obliquity of the incident light from Fresnel's formulæ. We find that, if we assume the refractive index of the window glass to be 1.51 , the loss at normal incidence in air is about $4.1 \%$. For oblique angles the loss increases, very slowly at first, and more and more rapidly with increasing obliquity. The air photometer was standardised in air at normal incidence, as described below, and hence the factor, $f$, by which the reading must be multiplied to correct for reflection losses, reduces to unity in this case. The values for other values of the obliquity are shown in the last column of the table.

The water photometer is calibrated at least once for each series by comparison with the air photometer. It is generally convenient to do 
this with the window covered with a shallow layer of water contained by the brass rim. This renders it unnecessary to haul the photometer on board and dry it before making a calibration at the end of a series of submarine measurements. It also almost entirely eliminates the screening out of light of altitude less than $10^{\circ}$, which would otherwise be caused by the rim. Thus during the calibration there are two reflecting surfaces in front of the diffusing surface, namely, the air-water surface and the water-glass surface. When measuring the illumination in the water we have only the latter to consider. The losses, for normal incidence, at the air-water and water-glass surfaces are found by calculation to be $2.0 \%$ and $0.4 \%$ respectively, the total loss being $1.7 \%$ less than it would be for a dry photometer. This reduction of loss due to the water was actually observed in some experiments in 1924.

The small loss at the water-glass surface is sensibly constant over the whole range of obliquity covered by the light in the water. As it, therefore, affects all calibrations and readings equally its effect is nil.

The loss at the air-water surface, however, only affects the calibration. We may correct for its effect by multiplying the calibration reading of the photometer by $\frac{\mathrm{V}_{\mathrm{a}}}{\mathrm{V}_{\mathrm{w}}}$. In this way we obtain the corrected value of the reading corresponding to the air illumination recorded by the air photometer.

\section{Standardisation of the Air Photometer.}

It has been shown by the Research Staft of the General Electric Co. (2) that the sensitivity of a vacuum photo-electric cell, such as is used in this photometer, is constant, and the current through the cell is very nearly proportional to the illumination. The photometer was accordingly standardised in the laboratory, and used in the marine observations to measure the light in air, and to calibrate the water photometer, whose sensitivity varied daily.

Both of the cells make use of potassium as an active element, and so their colour sensitivity should be somewhat similar.

Shinomiya (3) and Miss Seiler (4) have shown that the maximum sensitivity of these cells is in the neighbourhood of 4500 A.U., i.e. in the blue part of the spectrum. The cells accordingly measure chiefly blue light, and in standardising it is best to use a source as similar as possible to daylight. For this reason an open carbon arc was used to standardise the air photometer, although it is in other respects somewhat unsatisfactory, owing to its irregularity.

During the 1924 experiments a ground-glass window was used, and the sensitivity had been found to be 195 metre candles per potentiometer scale division $\left[10^{-4}\right.$ volt, equivalent to $1.95 \times 10^{-9}$ ampere]. As, however, 
doubt was felt as to the diffusing efficiency of the ground-glass surface at large obliquities, the window was subsequently replaced by the matt varnished one, mentioned above, and the photometer was restandardised.

A 36-watt 12-volt gas-filled lamp was compared by means of a flicker photometer first with a 16-C.P. standard carbon filament lamp working at 4.05 watts per candle, and then with an open carbon arc, carrying a current which was kept as nearly as possible at $10 \cdot 0$ amperes by hand regulation, the voltage across the arc being about 59.5 . The mean of four readings gave the candle power of the arc as 953, the maximum and minimum values being 1070 and 856 .

Five readings of the photometer were then taken with the arc at a distance of $50 \mathrm{~cm}$., and three with the arc at $30 \mathrm{~cm}$. from the window. The readings showed considerable variations, due to fluctuations in the arc, but the means of the two sets, $12 \cdot 7$ and $34 \cdot 5$ scale divisions, respectively, agree within $2 \%$ with the inverse square law. A sensitive galvanometer was used as a detector, thus considerably increasing the accuracy of the setting. As the "Zenite" resistance used at sea was not available, a similar one was used instead, its resistance being $48,070 \mathrm{ohms}$. The anode potential was 118.5 volts. With the resistance used at sea the sensitivity would be increased 1.067 times, while increasing the anode potential to 120 volts would raise it about $0 \cdot 45 \%$. Making allowance for these corrections we find that, with an anode potential of 120 volts one potentiometer division corresponds to 282 metre candles.

An alternative standardisation with a Mazda gas-filled "Daylight" lamp, i.e. a lamp with a blue-tinted bulb giving a light resembling daylight in appearance, gave 466 metre candles per scale division. This large difference may possibly be due to lack of ultra violet in the light of the metal filament lamp. It seems probable that arc light resembles daylight much more closely than does that of the "daylight" lamp as regards its effect on the photo-electric cell. Accordingly the are lamp standardisation has been used throughout, although there is little doubt that, as daylight is bluer than arc light, its effect on the photometer is relatively greater, so that the results found for daylight illumination on this photo-electric scale are all higher than they would be on the visual scale.

The effect of obliquity on the reading of the deck photometer was also tested, the "daylight" lamp being used as a constant source. The photometer readings, when corrected for reflection losses, should be proportional to the cosine of the angle of incidence. The readings decreased rather more rapidly than they should have done with increase of obliquity, until at an angle of incidence of $70^{\circ}$ the actual reading was only $96 \%$ of the theoretical. For still larger angles the readings apparently increased again (relatively) until the very small reading at 
$85^{\circ}$ was apparently slightly higher than the theoretical. These variations are probably chiefly due to lack of perfect diffusion in the window. As, however, they are of small importance compared with the variations in the light in the sea they may be neglected without serious error.

\section{Variations in the Sensitivity of the Water Photometer.}

As a vacuum cell such as is used in the air photometer would scarcely be sensitive enough for submarine measurements, the cell employed in the water photometer is of the Kunz gas-filled type. Shelford and Gail (5), who employed cells of this type in their work on submarine illumination, found that, for their cells, the current was not proportional to the illumination for values of the latter above 1000 metre candles. They relied on a single standardisation of their cells, and, apparently, were not troubled by changes of sensitivity, even though they used anode potentials from 80 to 160 volts with the cells exposed to bright light, and so obtained currents up to at least 24 microamperes. As, however, they did not re-standardise their cell it may possibly have varied considerably during the course of their work. With our cell any current exceeding 3 microamperes causes a rapid temporary increase in the sensitivity, and, even if precautions are taken to prevent the passage of such large currents, the sensitivity varies irregularly from day to day. To limit the current the anode potential employed is only about $18-20$ volts for bright light, and only increased to about 120 volts when the light is known to be weak enough for this to be done safely.

\section{Relation of the Illumination to the Current through the Water Photometer.}

On the other hand, if these precautions are taken, the current through our cell, at a given anode potential, is very nearly proportional to the illumination over the entire range, if the time interval between the readings is not too long. This proportionality was first proved for various anode potentials, and illuminations up to 25,000 m.c. by laboratory experiments with a lamp at different distances.

It is now tested afloat by means of a set of neutral tinted dark glass screens. The transmitting powers of these screens and their combinations at various angles of obliquity were measured in the laboratory, using the "daylight" lamp and the air photometer, as described in the previous paper (1). It was subsequently found, however, that the screens are appreciably more transparent to daylight than to the light of the lamp. Moreover, the transparency depends greatly on the obliquity, and so laboratory tests are not of very much use for finding the transmission 
factor for daylight, whose average angle of obliquity is generally only roughly known.

The best method of using the screens is to find the percentage transmitted by a given screen or combination, first with one photometer and then with the other, under, as nearly as possible, similar conditions. The results of such a set of tests is shown in Table 2 .

\section{TABLE 2.}

\begin{tabular}{|c|c|c|c|c|c|c|c|}
\hline Screens. & & I. & II. & $\mathrm{I}+\mathrm{II}$ & III. & I+III. & $\mathrm{II}+\mathrm{III}$ \\
\hline Photometer & . & 41 & 22 & 11 & $3 \cdot 7$ & $1 \cdot 7$ & $1 \cdot 1$ \\
\hline ercentage Transmitted. & Water & & & & & & \\
\hline Photometer* & . & 39 & 22 & $8 \cdot 8$ & $3 \cdot 6$ & $1 \cdot 5$ & $0 \cdot 9$ \\
\hline
\end{tabular}

The tests with the two photometers were made on successive days. Those with the air photometer being made in bright sunlight at an average altitude of $47^{\circ}$ and with $\mathrm{V}_{\mathrm{a}}=63,000$ m.c., the others also in bright sunlight of an average altitude $45^{\circ}$ and with $V_{\mathrm{a}}=75,000$ m.c. It would have been better to test each screen or combination first with one photometer and then with the other, but the idea of calibrating the screens once and for all had not been abandoned when these tests were made. It is evident that with an anode potential of 18 volts the current through the Kunz cell is, at least, approximately proportional to the light.

Similar tests were made with weak light and an anode potential of $119 \cdot 3$ volts on the Kunz cell, by keeping the window of the latter permanently covered by screen No. III and finding the effects of adding screens I and II. As the screens are not absolutely non-selective their transmission factors are not strictly multiplicative, and the factor for a combination must be found by trial. Unfortunately the air photometer is not sensitive enough to measure the transmission factor of a dense combination accurately, so that only approximate results could be obtained. These were satisfactory as far as they went, and showed that there was no evidence for suspecting that any change had occurred in the characteristics of the cell since it had been tested with weak illuminations and high anode potentials in the laboratory.

\section{Method of Taking Readings.}

The water photometer is suspended by a warp from a spar lashed to the mizzen boom so that it hangs about three feet clear of the counter, which is rather low with a steep "tumble home" to the bulwarks. Comparative readings of the photometer when suspended thus just clear of the

\footnotetext{
* Anode potential for Kunz cell $18 \cdot 0$ volts.
} 
surface, and on deck, respectively, showed that, with the ship's head in a suitable direction, the shading effect is small.

It is generally convenient to allow the ship to drift, when taking readings in fairly deep water. She generally lies more or less in the trough of the swell, so that the chief motion is rolling, which does not greatly affect the depth of submergence of the photometer below the mean water level. If the wind is strong, and the drift rapid, the upper end of the warp may make an appreciable angle, $\phi$, with the vertical. Owing to the weight of the photometer the lower end of the warp must be very nearly vertical. The curve assumed by the warp must be approximately parabolic, but may be treated as an arc of a circle without serious error. Then, to find the depth of submergence we must evidently multiply the apparent depth, which is measured on the warp, by $\frac{\sin \phi}{\phi}$, where $\phi$ is in circular measure. If $\phi$ is measured in degrees and does not exceed $30^{\circ}$, we may write this factor as $1-5 \times 10^{-5} \phi^{2}$. The correction is thus proportional to $\phi^{2}$ and amounts to $0.5 \%$ if $\phi=10^{\circ}$ and $2 \%$ if $\phi=20^{\circ}$, which was the limit reached with a manilla warp. A wire rope was used in the later experiments, so it is probable that this correction will be negligible in future.

The procedure generally adopted in 1925 was to work from the bottom up, the first reading being taken at the maximum depth, which was limited either by the depth of water or the length of the photometer leads. When working in deep water the light was so faint that about 120 volts could safely be applied to the Kunz cell. A set of readings at a given depth consists of an odd number of alternate readings of the two photometers, made at the briefest possible intervals, often about 20 seconds. Whichever photometer is read first is also read last, so that there is one more reading of it than of the other. Thus, there might be four of one and three of the other, or, if the light were somewhat variable, perhaps as many as nine of one and eight of the other. The mean of each set is taken as the reading of that photometer at the mean clock time of the sets. The reading of the air photometer multiplied by the reflection loss factor $f$, and by 282 , gives the vertical illumination in air, $\mathrm{V}_{\mathrm{a}}$.

Readings are taken at various depths until the light becomes so bright that further increase would necessitate a reduction in the anode potential applied to the Kunz cell. At this depth a triple set is taken, i.e. readings of the water photometer at about 120 volts, and also at about 20 volts, and of the air photometer, whose anode potential is always maintained at very nearly 120 volts. From these the relative sensitivities of the water photometer at the two pressures is found, thus enabling the deep readings to be reduced to what they would have been with the lower anode potential, which is used for the rest of the series.

The series concludes with the calibration set, which is taken with 
the water photometer just clear of the surface. This reading of the water photometer is multiplied by the reflection loss factor, as already explained, and the product is divided into the simultaneous ralue of $\mathrm{V}_{\mathrm{a}}$, as obtained from the air photometer reading. We thus find the number of metre candles per scale division of the water photometer for that particular series, and so find the actual illuminations at the different depths.

In some cases the water photometer was calibrated at the commencement, and also at the end of the series, and any small change of sensitivity which was observed was allowed for, the sensitivity being assumed to change uniformly with time. It is proposed always to adopt this procedure in future.

Another improvement would be the taking of readings both when descending and ascending, so that the deep readings come in the middle. This would generally reduce the effect of progressive changes in conditions such as the altitude of the sun or the position of the ship. These changes may, with the system adopted, cause a slight difference between the earlier, deep, and the later, shallow readings. That this effect is generally unimportant is shown by the fact that readings made quite out of the regular order usually accord quite well with the others. Some such irregular readings were specially made to test this point.

Readings of the "dark currents" of both photometers are made at intervals. No such current has ever been detected as actually passing through the photometers themselves. When a " dark current " is detected it always means that the insulating surfaces in the measuring apparatus are damp. This very seldom happens with the apparatus in the deck house, but occasionally a "dark current" of a couple of scale divisions was noted and allowance made for it.

In order that the results in a series should be as far as possible comparable, the conditions should be as uniform as possible. Thus if clouds are passing across the sky it is best to take readings at all depths with the sun shining. Extra readings with the sun obscured are of some interest. The relative proportions of sunlight and skylight may be deduced from the ratio, $\beta$, of the readings of the air photometer when exposed to, and shaded from, direct sun. This ratio is found at least once during each series, unless the sun is obscured, when of course, $\beta=1$. Rapid variations in light during a test are generally caused by variations in the direct sunlight. The corresponding change of $\beta$ is readily estimated on the assumption that the diffused light remains constant.

\section{RESULTS.}

The results of the 1925 measurements are given in Table 3, where T is the clock time (G.M.T.), $d$ the depth in metres, $V_{\mathrm{a}}$ and $\mathrm{V}$ the illuminations in metre candles found from the readings of the air and water 
photometers respectively, and $p=\frac{100 \mathrm{~V}}{\mathrm{~V}_{\mathrm{a}}}$. The letter $a$ in the depth column indicates that the water photometer was above the surface, the reading being a calibration.

In comparing these results with those given in the previous paper it must be remembered that the former were given in terms of the calculated total intensity I.

The results are plotted in Fig. 3 on a logarithmic scale. It is obviously necessary, in plotting the submarine illumination to correct for irregular variations in the surface illumination. This might be done by merely plotting the percentage, $p$, but the resulting six curves would be hopelessly superposed and confused, and it is more interesting to show the approximate values of the illumination. Accordingly, the mean surface illumination is found for each series, and the submarine illuminations for the series all reduced to the corresponding values. In one case [series 5 at $18.3 \mathrm{~m}$.], where duplicate sets of readings were made at one depth owing to rapid variations in the surface light, the result obtained with abnormally low surface light has not been plotted; it would be about $6 \%$ lower than the corresponding figure obtained with surface light nearer to the average for the series. Where there is a possibility of confusion circles of different sizes are used for different series. A vertical

\section{TABLE 3.}

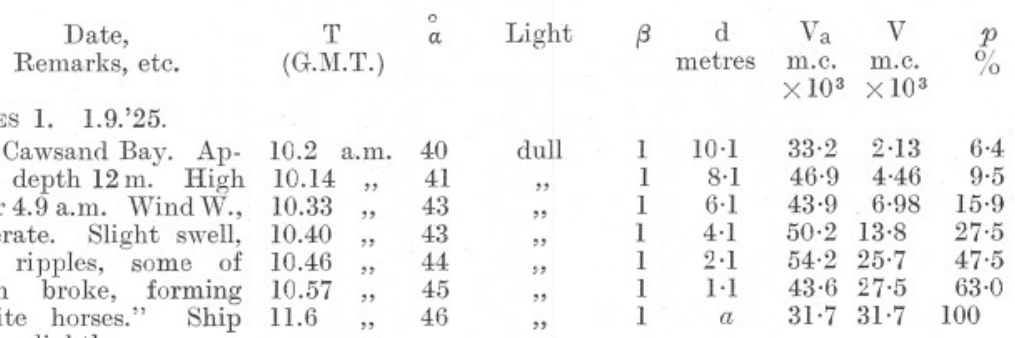

SERIES 2. 2.9.'25.

About 3 miles $\mathrm{S}$. of Mewstone. Approx. depth $40 \mathrm{~m}$. (chart). Wind W., moderate. Rise and fall of swell about $0.6 \mathrm{~m}$. Surface disturbed. Ship rolling slightly.

\begin{tabular}{|c|c|c|c|c|c|}
\hline 9.37 & i.m. & 37 & Bright sun & $3 \cdot 5$ & $34 \cdot 4$ \\
\hline 9.47 & , & 38 &,$\quad$, & $3 \cdot 5$ & $31 \cdot 8$ \\
\hline 9.55 & $"$ & 39 & , & .5 & $28 \cdot 7$ \\
\hline 0.5 & , & 40 & & 5 & $26 \cdot 0$ \\
\hline 0.10 & , & 40 & Cloud & 5 & $22 \cdot 7$ \\
\hline 10.14 & ", & 41 & Bright sun & $3 \cdot 5$ & $22 \cdot 7$ \\
\hline 0.20 & , & 41 & $"$ & $3 \cdot 5$ & $19 \cdot 8$ \\
\hline & , & & , & $\cdot 5$ & $20 \cdot 0$ \\
\hline & , & 42 & & $3 \cdot 5$ & $16 \cdot 9$ \\
\hline & , & 43 & Light cloud & $2 \cdot 5$ & $3 \cdot 8$ \\
\hline & ," & 43 & Sun & & $10 \cdot 8$ \\
\hline 10.5 & , & 44 & 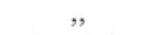 & & $7 \cdot 8$ \\
\hline 0.56 & ", & 44 & , & & $4 \cdot 7$ \\
\hline & & 45 &, & & \\
\hline
\end{tabular}

$\begin{array}{lll}75 \cdot 8 & 0 \cdot 28 & 0 \cdot 37 \\ 76 \cdot 7 & 0 \cdot 46 & 0 \cdot 60 \\ 72 \cdot 3 & 0 \cdot 69 & 0 \cdot 96 \\ 71 \cdot 3 & 1 \cdot 08 & 1 \cdot 52 \\ 37 \cdot 7 & 0 \cdot 84 & 2 \cdot 23 \\ 73 \cdot 6 & 2 \cdot 00 & 2 \cdot 72 \\ 73 \cdot 6 & 3 \cdot 31 & 4 \cdot 50 \\ 77 \cdot 5 & 3 \cdot 45 & 4 \cdot 45 \\ 84 \cdot 4 & 5 \cdot 53 & 6 \cdot 55 \\ 47 \cdot 0 & 5 \cdot 16 & 11 \cdot 0 \\ 63 \cdot 6 & 11 \cdot 7 & 18 \cdot 4 \\ 65 \cdot 0 & 19 \cdot 6 & 30 \cdot 2 \\ 63 \cdot 8 & 28 \cdot 6 & 44 \cdot 9 \\ 60 \cdot 7 & 60 \cdot 7 & 100\end{array}$


Date,
Remarks, etc.

Series 3. 2.9.'25.

In Cawsand Bay. Approx. depth 10-18 $\mathrm{m}$. (chart). High water $5 \cdot 6$ a.m. Fresh N.W. wind, causing rapid off-shore drift. Ship moved inshore between 2nd and 3 rd readings.

\section{Series 4. 3.9.'25.}

Anchored in Cawsand Bay. Depth, $10 \cdot 4 \mathrm{~m}$. at 9.50 a.m. (sounding). High water, 5.54 a.m. Fresh N.W. wind causing waves to break. No swell.

SERIES 5. 3.9.'25.

About 3 miles S. of 12.34 p.m. 4 Mewstone. Approx. depth $40 \mathrm{~m}$. (chart). High water 6.6 p.m. Fresh W. wind and considerable swell, lumpy surface. Ship rolling heavily.

Series 6. 1.10.'25.

At E1, 10 m. S.W. of 12.19 p.m. 36 Eddystone. Depth $72 \mathrm{~m}$. 12.31 , 37 (sounding). Light air, 12.40 ,, 36 N.N.W. Very slight oily $12.53,, \quad 35$ $\begin{array}{llll}\text { swell, glassy surface. } & 1.18, & 35 \\ \end{array}$

$1.35, ", 34$

$1.46, \quad 33$

$1.58, \quad 32$

$2.11 " 31$

\begin{tabular}{|c|c|c|c|c|c|}
\hline Light & $\beta$ & $\begin{array}{c}\mathrm{d} \\
\text { metres }\end{array}$ & $\begin{array}{l}V_{\mathrm{a}} \\
\text { m.c. } \\
\times 10^{3}\end{array}$ & $\begin{array}{c}V \\
\text { m.c. } \\
\times 10^{3}\end{array}$ & $\begin{array}{c}p \\
\%\end{array}$ \\
\hline Dull & 1 & $10 \cdot 2$ & $20 \cdot 8$ & $3 \cdot 02$ & $14 \cdot 5$ \\
\hline , & 1 & $8 \cdot 15$ & $20 \cdot 5$ & $3 \cdot 94$ & $19 \cdot 2$ \\
\hline . & . & . & & & \\
\hline , & 1 & $6 \cdot 35$ & $15 \cdot 8$ & $3 \cdot 09$ & $19 \cdot 6$ \\
\hline , & 1 & $4 \cdot 4$ & $13 \cdot 7$ & $4 \cdot 26$ & $31 \cdot 1$ \\
\hline , & 1 & $2 \cdot 2$ & $12 \cdot 6$ & $6 \cdot 65$ & $52 \cdot 8$ \\
\hline ", & 1 & $1 \cdot 25$ & $13 \cdot 4$ & 8.67 & $64 \cdot 7$ \\
\hline , & 1 & $4 \cdot 2 \dagger$ & $15 \cdot 6$ & $5 \cdot 81$ & $37 \cdot 3$ \\
\hline & 1 & $a$ & $18 \cdot 5$ & 18.5 & 100 \\
\hline
\end{tabular}

Bright sun
,$"$,
,$"$,
,$"$,
,$"$,
,$"$,
,$"$,
,$"$,

$\begin{array}{cccc}a & 65 \cdot 8 & 65 \cdot 8 & 100 \\ 5 \cdot 9 \dagger & 64 \cdot 8 & 19 \cdot 8 & 30 \cdot 5 \\ 10 \cdot 35 * & 65 \cdot 6 & 7 \cdot 42 & 11 \cdot 3 \\ 9 \cdot 85 & 66 \cdot 1 & 11 \cdot 5 & 17 \cdot 4 \\ 8 \cdot 3 & 66 \cdot 1 & 14 \cdot 1 & 21 \cdot 3 \\ 6 \cdot 5 & 69 \cdot 3 & 19 \cdot 0 & 27 \cdot 4 \\ 4 \cdot 35 & 70 \cdot 3 & 25 \cdot 8 & 36 \cdot 7 \\ 2 \cdot 35 & 74 \cdot 0 & 37 \cdot 8 & 51 \cdot 1 \\ a & 68 \cdot 7 & 68 \cdot 7 & 160\end{array}$

$\begin{array}{clcccc}\text { Dull } & 1 & a & 24 \cdot 2 & 24 \cdot 2 & 100 \\ \text { Weak sun } & 1 \cdot 5 & 30 \cdot 8 & 39 \cdot 1 & 0 \cdot 04 & 0 \cdot 10 \\ \text { Dull } & 1 & 24 \cdot 3 & 27 \cdot 2 & 0 \cdot 78 & 2 \cdot 87 \\ \text { ", } & 1 & 18 \cdot 3 & 15 \cdot 55 & 1 \cdot 01 & 6 \cdot 49 \\ \text { W", sun } & 1 & 18 \cdot 3 & 31 \cdot 4 & 2 \cdot 15 & 6 \cdot 85 \\ \text { Weak sun } & 2 & 12 \cdot 5 & 48 \cdot 1 & 7 \cdot 82 & 16 \cdot 3 \\ \text { " Dull" } & 2 & 6 \cdot 45 & 46 \cdot 6 & 15 \cdot 3 & 32 \cdot 9 \\ & 1 & a & 20 \cdot 6 & 20 \cdot 6 & 100\end{array}$

\begin{tabular}{|c|c|c|c|c|c|c|}
\hline \multicolumn{2}{|c|}{ Dull } & 1 & $34 \cdot 8$ & $17 \cdot 4$ & 0.094 & $0 \cdot 54$ \\
\hline \multicolumn{2}{|c|}{ " } & 1 & $24 \cdot 4$ & $16 \cdot 0$ & $0 \cdot 47$ & $2 \cdot 93$ \\
\hline & & 1 & $18 \cdot 3$ & $18 \cdot 3$ & $1 \cdot 45$ & $7 \cdot 92$ \\
\hline \multicolumn{2}{|c|}{ Weak sun } & $1 \cdot 5$ & $12 \cdot 2$ & $21 \cdot 3$ & $3 \cdot 97$ & $18 \cdot 6$ \\
\hline$"$ &, & 1.5 & $8 \cdot 9^{\dagger}$ & $20 \cdot 4$ & $5 \cdot 77$ & $28 \cdot 3$ \\
\hline , & ," & 1.5 & $34 \cdot 8$ & $24 \cdot 5$ & $0 \cdot 132$ & 0.54 \\
\hline , & ," & 1.5 & $6 \cdot 1$ & 2.5 & $9 \cdot 28$ & $41 \cdot 2$ \\
\hline , & ," & 1.5 & $1 \cdot 5$ & $21 \cdot 1$ & $15 \cdot 0$ & 71 \\
\hline , & ,, & $1 \cdot 5$ & $a$ & $22 \cdot 4$ & $22 \cdot 4$ & 100 \\
\hline
\end{tabular}

line through a plotted point indicates the depth at which the anode potential of the water photometer was changed; the higher voltage being used for the deeper readings, and vice versa.

It will be observed that, with a few exceptions referred to later, the results lie tolerably well on curves, which for the shallow series cannot be distinguished from right lines. These curves are produced above the line corresponding to the water surface until they intersect the corresponding vertical lines indicating the mean values of the surface illumination for the respective series. The intercept on the surface line between a

* Photometer resting on bottom.

$\dagger$ Depth chosen so that photometer window just visibie. 


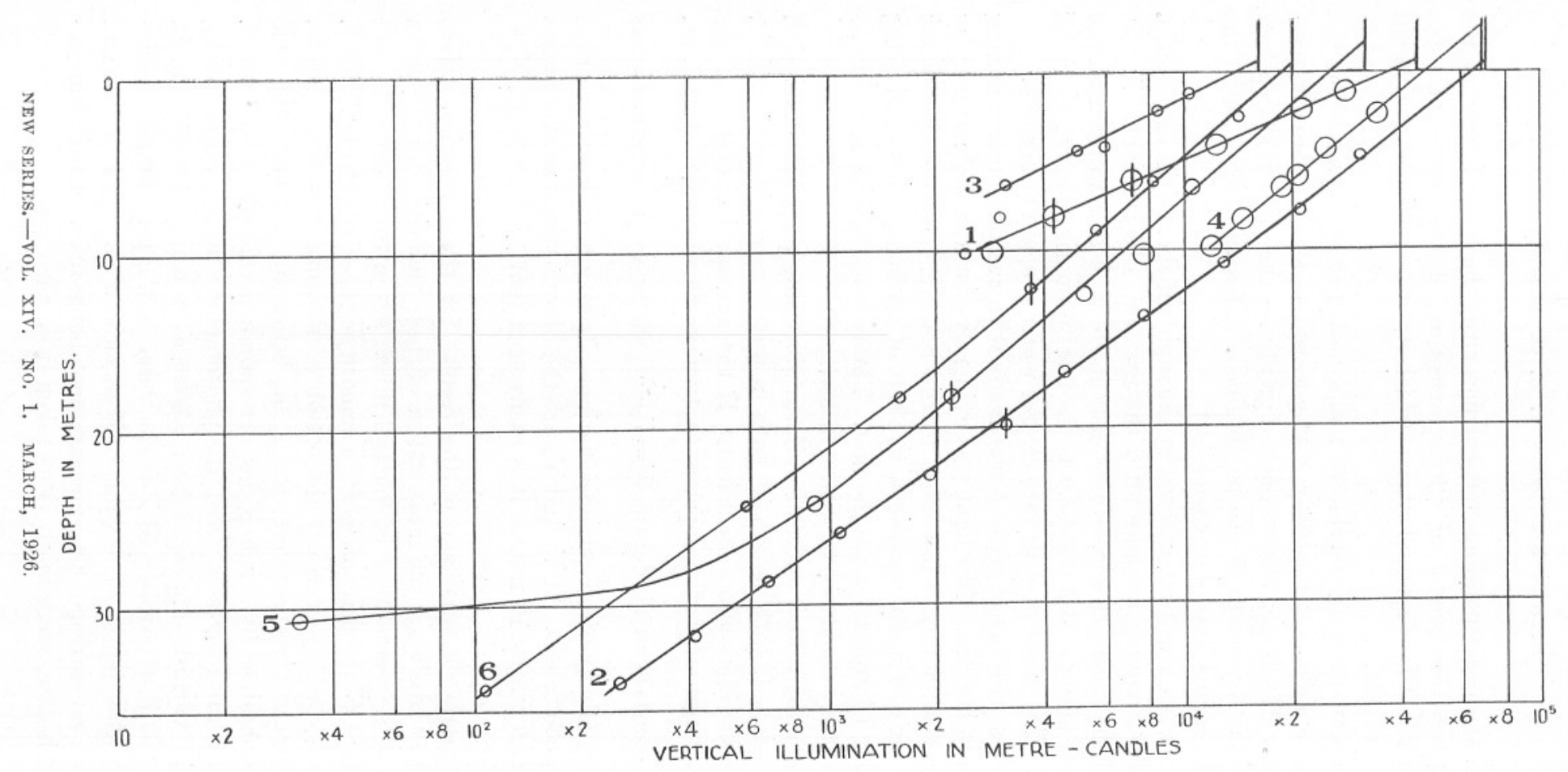

FIG. 3. 
curve and the corresponding vertical measures the loss of light at the surface, while the height of the intersection of the curve and the vertical gives the depth of water which would cause an equivalent reduction in light.

It is unfortunately impossible to make measurements just below the surface as the light is so unsteady, owing to waves, that a balance cannot be effected. The larger the waves the greater is the minimum depth at which satisfactory readings can be obtained. This, of course, limits the accuracy of estimations of surface loss.

The results in series 3 are affected by the rapid off-shore drift of the ship. This involved moving in-shore after the first two observations. It will be noticed that these two were obviously made in clearer water than the rest. The reading at $4 \cdot 2$ metres was the last submarine measurement of the series. The effect of drift into clearer water is again noticeable.

The deepest reading of series 4 was made with the photometer resting on the sandy bottom. The light was evidently considerably reduced by a thin layer of cloudy water close to the bottom. The deepest point plotted in series 6 really represents two sets of readings, the second being made 1 hour 16 minutes after the first. The reduced results accorded so closely that they could not be distinguished.

For parallel light and water of uniform absorbing power the variation of illumination, $\mathrm{I}$, with length of path in water, $x$, would be $\mathrm{I}=\mathrm{I}_{0} \mathrm{e}^{-\mu x}$, where $\mu$ is the absorption coefficient. If the average inclination of the light, $\theta$, does not vary with depth we may write this $\mathrm{I}=\mathrm{I}_{0} \mathrm{e}^{-\mu \mathrm{d} \operatorname{cosec} \theta}$, or, since $\frac{\mathrm{I}}{\mathrm{V}}$ is constant at all depths, $\mathrm{V}=\mathrm{V}_{0} \mathrm{e}^{-\lambda \mathrm{d}}$, where $\lambda=\mu \operatorname{cosec} \theta$, and is what we actually find from our observations. It may be called the vertical absorption coefficient. If $\mathrm{V}_{1}$ and $\mathrm{V}_{2}$ are the illuminations at two points differing in depth by 10 metres it is easily seen that $\lambda=0 \cdot 23\left[\log _{10} \mathrm{~V}_{1^{-}}\right.$ $\log _{10} \mathrm{~V}_{2} \mathrm{~J}$.

Table 4 shows a summary of the results for the six series. Here $\mathrm{V}_{\mathrm{a}}, \alpha, \beta$, and $\operatorname{cosec} \theta$ are the mean values of these quantities for the given series. $\mathbf{S}$ is the percentage of vertical illumination transmitted by the actual surface, $\mathrm{S}^{\prime}$ the percentage for a smooth surface found from Table 1 . $\lambda_{1}, \lambda_{2}$, and $\lambda_{3}$ are the vertical absorption coefficients from 0-10, 10-20, and 20-30 metres, respectively, $\mu_{1}, \mu_{2}, \mu_{3}$ being the corresponding true coefficients obtained by dividing the corresponding values of $\lambda$ by $\operatorname{cosec} \theta$. $\mathrm{D}$ is the depth in metres at which the photometer window, which, owing to the matt varnish, appeared from above as a white disc $6.6 \mathrm{~cm}$. in diameter, was just visible, and $\mathrm{P}$ is the value of the percentage $p$ corresponding to this depth. The value of $\mathrm{D}$ in series 2 was found at the end of the series, no corresponding measurement being made of the illumination. In this case, accordingly, $\mathrm{P}$ is taken from the curve. 
TABLE 4.

\begin{tabular}{|c|c|c|c|c|c|c|c|c|c|c|c|c|c|c|}
\hline Seri & $\begin{array}{l}\text { es. } V_{\mathrm{a}} \\
\times 10^{3} \\
\text { m.c. }\end{array}$ & $\stackrel{\circ}{a}$ & $\beta$ & $\operatorname{cosec} \theta$ & $\begin{array}{l}\mathrm{S} \\
\%\end{array}$ & $\begin{array}{l}S^{\prime} \\
\%\end{array}$ & $\lambda_{1}$ & $\lambda_{2}$ & $\lambda_{3}$ & $\mu_{1}$ & $\mu_{2}$ & $\mu_{3}$ & $\begin{array}{c}\mathrm{D} \\
\text { metres }\end{array}$ & $\begin{array}{l}\mathrm{P} \\
\mathrm{s} \%\end{array}$ \\
\hline 1 & 45 & $43^{\circ}$ & 1 & $1 \cdot 19$ & 83 & $93 \cdot 5$ & 0.267 & - & - & $0 \cdot 224$ & - & - & - & - \\
\hline 2 & 70 & $41^{\circ}$ & 3 & $1 \cdot 21$ & $90 \cdot 5$ & 96 & $0 \cdot 148$ & $0 \cdot 163$ & $0 \cdot 164$ & 0.122 & 0.135 & $0 \cdot 136$ & $7 \cdot 0$ & 33 \\
\hline 3 & 16 & $31^{\circ}$ & 1 & $1 \cdot 19$ & $86 \cdot 5$ & $93 \cdot 5$ & $0 \cdot 234^{*}$ & - & - & 0.196 & - & - & $4 \cdot 2$ & $37 \cdot 3$ \\
\hline 4 & 68 & $39^{\circ}$ & 3 & $1 \cdot 21$ & 69 & 96 & $0 \cdot 139$ & - & - & $0 \cdot 115$ & - & - & $5 \cdot 9$ & $30 \cdot 5$ \\
\hline 5 & 32 & $44^{\circ}$ & $1 \cdot 5$ & $1 \cdot 19$ & $79 \cdot 5$ & 95 & $0 \cdot 131$ & $0 \cdot 138$ & $0 \cdot 296$ & $0 \cdot 110$ & $0 \cdot 116$ & $0 \cdot 248$ & - & - \\
\hline 6 & 20 & $34^{\circ}$ & $1 \cdot 5$ & $1 \cdot 22$ & 95 & 94 & $0 \cdot 134$ & $0 \cdot 143$ & $0 \cdot 162$ & 0.110 & $0 \cdot 117$ & $0 \cdot 133$ & $8 \cdot 9$ & $28 \cdot 3$ \\
\hline
\end{tabular}

\section{Discussion of Results.}

The surface loss of light evidently increases with the disturbance of the water caused by wind. In series 6 , with hardly any wind and only a slight swell the surface loss is about what we would expect for a smooth water, while the largest loss occurred with a strong wind in series 4 . In most cases the loss is considerably less than that found by either Shelford and Gail or Klugh (6). It should be noted that, in all cases the vertical illumination, $\mathrm{V}$, is referred to, the reduction in total illumination, I, being considerably larger, as already pointed out.

Shelford and Gail exposed their photo-electric cell directly to the water without any diffusing surface, since they required the utmost sensitivity in view of the considerable depth to which they worked. This unfortunately complicates the interpretation of their results for the surface loss, as the presence of a short focus diverging water lens, formed by the water between the curved surface of the cell and the surface, would strongly affect the path of the rays entering the cell. Even if the entire inner surface of the cell, other than the pupil, were coated with a uniformly sensitive layer, it is probable that some light striking obliquely near the edge of the pupil would be totally reflected, and never enter the cell. This effect would probably be increased by the presence of ripples on the surface, which would in general cause an increase in the average angle made by the light with the vertical.

Klugh gives a single result, $77 \%$, for the light transmitted by a smooth surface in the Bay of Fundy. This is lower than most of our results though not so low as that for series 4 .

As might, perhaps, be expected, the in-shore readings generally show relatively large absorption coefficients, although series 4 is an exception, in showing a small coefficient until quite near the bottom. The clearest water was found well off-shore at $\mathrm{E}_{1}$, although the difference is not very marked.

The apparent increase of absorption coefficient with depth, which is found in all the off-shore readings may possibly be due to a lack of strict proportionality between the illumination and the current through the

\footnotetext{
* Obtained from measurements down to 6 metres only.
} 
Kunz cell. To test this point a specially sensitive vacuum cell is being constructed for us to replace the Kunz cell.

This explanation would, however, certainly not explain the pronounced curvature found in series 5 , and it seems probable that the slight curvatures shown by Nos. 2 and 6 also represent real increases, which may be due, either to scattering, which would cause the average inclination, and hence the penetrating power, of the light to decrease with increase of depth, or to the presence in the deeper layers of matter derived from the bottom. This is certainly the explanation of the low reading obtained on the bottom in series 4 , and probably that of the low reading obtained at 30.8 metres, on a very rough day, in series 5 .

The absorption coefficients are all much smaller than those obtained in 1924 for the comparatively turbid waters at Cawsand Pier. The offshore values down to 20 metres are somewhat smaller than those indicated by Shelford and Gail on p. 162 of their paper, where, however, transmission coefficients are given. Thus, in spite of the lower solar altitude, the mean of these three series gives an illumination at 20 metres, about $5 \cdot 5 \%$ of that just below the surface, whereas their mean figure is $2.5 \%$ (p. 156). Thus the surface water in the English Channel off Plymouth seems to be somewhat clearer than that in Puget Sound. On the other hand Shelford and Gail worked to much greater depths than we have reached, and found a large reduction in the absorption coefficient with increase of depth, showing that the deeper water in Puget Sound is much more transparent than any water which we have met.

Klugh, using a photographic method, found, for bright sunlight in the month of August, that the light at a depth of 10 metres in the Bay of Fundy was only $1.5 \%$ of that just below the surface. As our equivalent off-shore mean figure is about $23 \%$ it is obvious that the water where he worked was much more opaque than that which we found off-shore. His results, however, are very similar to those which we obtained in 1924 at Cawsand Pier.

The results may also be compared with those of Knudsen ( $\boldsymbol{y})$, who, using a spectro-photographic method in water 9 metres deep in Nyborg Fjord, found a mean value 0.30 for the vertical absorption coefficient for light of wave length 4500 A.U. This is intermediate between the values for our 1925 in-shore measurements and our 1924 measurements at Cawsand Pier.

The figures for the depth and percentage of surface light at which the photometer window is just visible are of some interest in connection with the large number of observations that have been made with Secchi's disc, although they are not strictly comparable with the latter, since the photometer window is only about one-third the diameter of, and is probably not so white as the disc. Apparently the limit of visibility is 
reached when the vertical illumination has been reduced to about onethird of that above the surface. This appears to be nearly independent of the actual value of the surface illumination over a wide range. The vertical illumination required to see the disc was naturally least in calm water.

In this connection it is of interest to record the fact that the German diver who went down in the new diving apparatus to look for Submarine M 1 was able to see a slender rope at 5 metres distance at a depth of 40 metres between 4 and 4.30 p.m., on November 25 th, a dull overcast day with a rough sea. Captain G. C. Damant, R.N., who kindly communicated this to us, is of the opinion that the water in this locality, off Start Point, Devon, to the east of Plymouth, was exceptionally clear as judged by his own experience as a diver. The surface conditions were apparently somewhat similar to those for our series 5, and the total depth of water was also about the same, but the surface light must have been very much less, possibly about 3000 metre candles. The remarkable visibility suggests that the water near the bottom was not as much obscured by matter in suspension, as in our series 5. Assuming the clear water conditions of our series 6 , and extrapolating to 40 metres, the vertical illumination would be 0.25 per cent of that at the surface. Thus we would expect the vertical illumination on this occasion to have been of the order of 10 metre candles. Since, however, the weather had been rough previously and the diver was actually on the bottom the illumination may have been considerably less.

\section{SUMMARY.}

1. A description is given of some measurements of the penetration of light into sea-water carried out near Plymouth in the autumn of 1925 by means of photo-electric cells, the current through the cell being measured by a method, previously described, which is not affected by the motion of the ship.

2. The absorption coefficients found for off-shore waters down to 30 metres are smaller than the average of those found by several recent. observers in various localities, but considerably larger than those found by Shelford and Gail for the deeper waters of Puget Sound. The coefficients tend to increase with increase of depth, and are generally larger for in-shore waters. The clearest water, 20 miles out in the English Channel, gave an absorption coefficient $0 \cdot 110$ for the upper 10 metres, 0.117 for the second, and $0 \cdot 133$ for the third. This water, with glassy surface, transmitted $0.54 \%$ of the vertical illumination to 34.8 metres, $28.3 \%$ to 8.9 metres, at which depth a white disc was just visible, and $71 \cdot 2 \%$ to 1.5 metres. 
3. The loss of light caused by surface reflection was not so large as has been recorded by some other workers, but varied from $5-31 \%$ according to conditions ; the least loss was with glassy water and a grey sky, the greatest was with a fresh N.W. wind causing waves to break, viz. "white horses," without much swell.

In conclusion we wish to express our sincere gratitude to Dr. Allen, Director of the Marine Biological Laboratory, for the laboratory and marine facilities which have rendered this work possible; to Prof. W. E. Thrift, of Trinity College, Dublin, where most of the laboratory work was carried out, for laboratory facilities and the loan of valuable apparatus; to Prof. Joly for the loan of further apparatus ; and to the Committee of Science of the Royal Dublin Society for their kind permission to make use of blocks from a paper in the Society's Scientific Proceedings.

\section{REFERENCES.}

1. Poole, H. H. On the Photo-Electric Measurement of Submarine Illumination. Scient. Proc. R. Dub. Society, 1925, 18, No. 9, 99-115.

2. Research Staft of the General Electric Company. Letter to "Nature," April 26, 1924.

3. Shinomiya, T. Color Sensitiveness of Photo-Electric Cells. Astrophys. Jour., 1919, 49, No. 5, 303.

4. SeIler, Miss E. F. Color Sensitiveness of Photo-Electric Cells. Astrophys. Jour., 1920, 32, No. 3, 129.

5. Shelford, V. E., and GaIl, F. W. A Study of Light Penetration into Sea-water made with the Kunz Photo-Electric Cell with Particular Reference to the Distribution of Plants. Publications, Puget Sound Biological Station, 1922, 3, No. 65, 141-176.

6. Klugh, A. B. Ecological Photometry and a New Instrument for Measuring Light. Ecology, 1925, 6, 3, 203-237.

7. Knudsen, M. On Measurement of the Penetration of Light into the Sea. Conseil Permanent International pour l'Exploration de la Mer. Publications de Circonstance, No. 76, Nov., 1922. 